A AUTORA

Maria Ignês Carlos Magno

Professora de História no ensino fundamental e mé-

dio em São Paulo. Doutora em Ciências da Comuni-

cação pela ECA-USP.

\title{
ESCRITA COMO TEMA DE PESQUISA
}

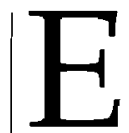

mbora ainda não tenhamos compreendido tudo o que mudou e vem mudando no mundo e nos espaços escolares com o advento e o rápido desenvolvimento das tecnologias e, em particular, com as tecnologias educacionais, sabemos que elas estão aí e que nossa prática pedagógica precisa ser repensada.

Repensar não significa anular ou negar o que sabemos e fazemos, mas pensar de novo o nosso trabalho em sala de aula à luz das mudanças. É importante repensarmos nossa posição enquanto professores, pois se às vezes temos dificuldade em entender os mecanismos técnicos ou resistimos em aceitar que a tecnologia e os meios de comunicação já fazem parte de um discurso do cotidiano; precisamos tentar superar debilidades para reconhecer e incorporar esta nova realidade às nossas atividades e práticas escolares. Mesmo porque, devido às exigências sociais e de mercado, nos é cobrado o conhecimento de conceitos que agitam os meios educa- cionais embora, na maioria das vezes, não nos tenha sido dada oportunidade para a necessária atualização.

Levando em conta estas preocupações. dividi em duas as sugestões de filmes para este número da revista. Na primeira parte proporei, como eixo da recuperação da compreensão dos saberes, tratar sobre a mais antiga das práticas escolares: a escrita. Na segunda parte, darei continuidade à discussão, iniciada em números anteriores, sobre a pesquisa como estrutura de conhecimento. Os filmes selecionados são: Ninguém escreve ao coronel, Central do Brasil e $O$ trem da vida.

\section{NINGUÉM ESCREVE}

AO CORONEL (El coronel no tiene a quiem le escriba)

Diretor: Arturo Ripstein

Produção: Jorges Sandoz

Roteiro: Paz Alicia Garciadiego

Montagem: Fernando Pando

Fotografia: Guillermo Granillo 
Música: David Mansfield

Duração: $118 \mathrm{~min}$

Ano: 1999

País: México

O filme é uma adaptação do romance homônimo de Gabriel Garcia Marques. Semana após semana o Coronel se veste solenemente e fica parado diante do cais, aguardando a carta que anunciará a chegada de sua tão esperada pensão. Todos do vilarejo sabem que ele espera em vão, inclusive sua mulher, que há anos o vê preparar-se diante do espelho para receber a carta que nunca chegou.

\section{CENTRAL DO BRASIL}

Direção: Walter Salles

Roteiro: João Emanuel e Marcos Bernstein

Fotografia: Walter Carvalho

Montagem: Isabelle Rathery e Felipe Lacerda

Som: Jean Claude Bresson

Música: Antônio Pinto e Jaques Morelenbaum

Duração: $112 \mathrm{~min}$

Ano: 1998

País: Brasil

Dora escreve cartas para analfabetos na estação Central do Brasil. Uma de suas clientes é Ana, que vem escrever uma carta para o marido, com o seu filho, Josué, um garoto de nove anos, que sonha encontrar o pai que nunca conheceu. Na saída da estação Ana é atropelada e Josué fica abandonado. Mesmo a contragosto, Dora acaba acolhendo o menino e envolve-se com ele. Termina por levar Josué para o interior do Nordeste, à procura do pai. À me- dida que vão viajando Brasil adentro, esses dois personagens vão se aproximando. Começa então uma viagem fascinante ao coração do Brasil, à procura do pai desaparecido, e uma viagem profundamente emotiva ao coração de cada um dos personagens.

\section{ESCRITA E ANALFABETISMO}

Os dois primeiros filmes têm na escrita o seu tema básico e a carta o meio através do qual os contatos serão feitos e os sonhos realizados. O Coronel espera a aposentadoria a que tem direito. Josué espera encontrar o pai que nunca conheceu. $\mathrm{O}$ primeiro filme é adaptação do romance de Gabriel Garcia Marques e trata da angústia do coronel que aguarda sua aposentadoria. A história se passa num vilarejo sem nome porque pode ser qualquer vilarejo da América Latina ou do mundo. São espaços e tempos indefinidos, podem ser qualquer tempo e espaço na medida em que as pessoas e os vilarejos foram esquecidos das autoridades, do progresso, da vida dos grandes centros.

O realismo tantástico caracterizou muito da produção literária dos anos das ditaduras latino-americanas.

Esta era uma forma de representar muitos dos embates que aconteciam na realidade e a resistência, mesmo que às vezes mostrada através da espera incansável de que um dia as coisas mudariam.

Gabriel Garcia Marques é colombiano, e a pesquisa pode ser iniciada pelo mapeamento da vida e da produção literária do autor, bem como pela história 
da Colômbia, como parte de uma história da América Latina. Os grupos étnicosociais que formaram o povo, a diversidade cultural, os avanços intelectuais e sua situação política e econômica no atual quadro das relações entre Norte e Sul, entre o discurso das livres negociações e as relações de dominação e poder entre países ricos e pobres.

Pode-se, também, pesquisar a história da Colômbia e até da América através dos outros contos e romances do autor e dos autores que compuseram esse movimento literário, o realismo fantástico. Seria um exercício interessante, além das muitas leituras e interpretações que os elementos simbólicos do filme nos propõem.

Enquanto o Coronel espera no cais o barco que trará, através do rio, a carta que mudará sua vida, Dora escreve, da Central do Brasil - da estação de trem -, para todos aqueles que vivem nos mais diferentes locais do país.

Dora escreve para analfabetos que querem por meio da escrita e da carta se comunicar, mandar suas mensagens. O desejo do contato, do reencontro, do simples dizer estou aqui, faz com que as pessoas externem os mais íntimos desejos e sonhos: os sonhos de muitos Josués. O desejo duplamente revelado: o desejo de conhecer o pai e o de dominar a escrita quando determina a Dora "Escreva aî". Sua mãe é analfabeta assim como $13 \%$ da população brasileira, apesar dos desenvolvimentos tecnológicos desse início de século.

Embora sabendo que muitos trabalhos já foram feitos com esse filme e outros tantos serão, resolvi indicá-lo sob esta ótica: da escrita. A escrita é uma técnica, uma ferramenta necessária - principalmente hoje com as novas tecnologias -, porque escrever é um ato reflexivo. Refletir pressupõe um movimento interno de meditação, de pensamentos que se deixam revelar. Como o filme nos leva aos muitos corações do Brasil, e sugere que façamos uma visitação atenta aos interiores do país e de nós mesmos, gostaria de propor alguns temas que proporcionem o debate sobre os problemas brasileiros com os quais convivemos e sobre os quais precisamos pensar; e também sobre os aspectos que nos permitam revelar características de nossa cultura popular, as quais, muitas vezes, ignoramos.

Já que a idéia é repensar a prática, um dos principais temas é o próprio analfabetismo. A partir dos atuais dados do IBGE, proponha uma pesquisa sobre a educação no Brasil, sobre os movimentos de educação popular, especialmente as experiências desenvolvidas no Nordeste no início dos anos $60^{1}$, sobre Paulo Freire e suas propostas de ensino. Promova uma discussão sobre as propostas de Paulo Freire e as da atualidade; e sobre a escola pública durante o regime militar e hoje.

Outro tema que pode ser pesquisado é a história das migrações para o Sudeste

\footnotetext{
1. Paulo Freire foi convidado pelo Ministro da Educação, Paulo Tarso Santos, no governo de João Goulart, a coordenar o programa nacional de Alfabetização, oficializado em 21 de janeiro de 1964 , pelo Decreto $n^{\circ} 53.465$ e extinto em 14 de abril do mesmo ano pelo golpe militar. (N. Ed.)
} 
nas décadas de 30/50/70; e Centro-Oeste, na década de 80 . Por que vieram os nordestinos? Para que vieram? Onde vivem hoje e o que fazem nos grandes centros? Das histórias das migrações, podemos recuperar histórias de vida dos alunos, de seus parentes, de nós professores, porque de alguma forma somos todos migrantes. Realizar uma pesquisa sobre o grau de instrução e o porquê do analfabetismo entre estas camadas da população também é interessante. A exposição dos dados, a elaboração de gráficos dos resultados, com a colaboração da disciplina de Matemática e Informática (se houver) e a socialização dos mesmos torna visível o quadro de situações e favorece os debates. Quanto às histórias de vida, organizá-las em um livro, ilustrado se possível, ou ainda, apresentar, em forma de seminário, o que aprendemos sobre o Brasil a partir das histórias pessoais.

Mesmo sabendo que muitas escolas e professores dispõem de recursos, acesso aos meios e às tecnologias de ponta, ao sugerir a escrita como eixo de compreensão dos saberes, pensei naqueles que não têm acesso, mas que podem e devem lançar mão de todos os meios que estiverem ao alcance para produzir.

O importante é a organização

em torno de uma idéia, de um projeto de pesquisa.

Como o foco é a escrita e suas muitas formas de escrever, sugiro a correspondência como meio de comunicação, a carta, eletrônica ou não, como veículo e espaço de reflexão e, principalmente, de conversação e registro.
O terceiro filme Trem da Vida será usado ao mesmo tempo como sugestão e relato de uma experiência realizada numa classe de primeiro ano do curso de pedagogia do Centro Universitário SalesianoUNISAL.

TREM DA VIDA (Train de vie)

Roteiro e direção: Radu Mihailearnu

Montagem: Monique Rysselinck

Fotografia: Yorgos Arvanitis, Laurrent

Dailland

Música: Goran Bregovic

Duração: 103min

Ano: 1998

País: Romênia/França

De acordo com a sinopse, o filme se passa num vilarejo na Europa Oriental, no ano de 1941. Os moradores recebem o alerta de que os nazistas estão chegando para deportar e matar todos os judeus. Quem dá a notícia é Schlomo, o bobo da aldeia, o único capaz de sugerir uma saída: os próprios habitantes irão forjar um trem nazista, fazendo eles mesmos a vez dos alemães, do maquinista e dos deportados. Antes da chegada dos verdadeiros nazistas, o trem parte com destino à terra prometida. Tudo sai conforme o planejado, exceto pelo fato de que as encenações começam a ficar cada vez mais realistas. Os moradores disfarçados de nazistas se tornam mais autoritários, os que se passam por deportados começam a tramar uma rebelião contra seus falsos algozes e outros se declaram comunistas, querendo lutar contra fascistas, burgueses e imperialistas.

A proposta de trabalho com este filme pode também partir de uma simu- 
lação: peça aos alunos que assistam ao filme e considerem-se em duas situações - como alunos e como professores. Como alunos, deveriam anotar tudo que gostariam de saber sobre o filme e a história contada; como professores deveriam construir uma proposta de pesquisa sobre o tema. No exercício que realizei com os alunos a experiência transcorreu assim: tiveram uma semana para elaborar a prova. No dia combinado, respondi, por duas horas, perguntas de história e as sugestões de pesquisa foram entregues.

Depois da leitura, agrupei as questões formuladas e selecionei uma das propostas como indicação de pesquisa. Embora muitas das sugestões merecessem atenção, os critérios, neste momento, foram o enfoque e a criatividade.

Todos, no entanto, compuseram a relação dos temas sugeridos para pesquisa.

Das várias propostas, organizei em quatro os grupos de temas para pesquisas: a pesquisa histórica propriamente dita, como estudos sobre a Segunda Guerra, sobre o Socialismo, Nazismo, Fascismo, sobre os motivos das perseguições dos judeus e dos ciganos, sobre os conflitos atuais entre Judeus e Palestinos. Num segundo e maior grupo os temas recaíram sobre as culturas judaica e cigana. Num terceiro grupo ficaram as pesquisas simbólicas como análise de trechos e falas como: "Vamos viajar para outros espaços do céu. Espaço do coração", ou ainda os diálogos entre as crianças com a mãe sobre "o significado da Terra Santa", os diálogos políticos entre os socialistas e os nazistas, a história contada para as crianças sobre a importância da liberdade. O quarto tema foi a guerra em si. Uma guerra que mesmo não aparecendo rondava os povos.

Este exercício exige do aluno o olhar mais atento sobre o filme bem como um certo amadurecimento para identificar e elaborar propostas de estudo da realidade, a partir de um produto dos meios de comunicação. Finalizando, segue o roteiro proposto pela aluna Carolina Rosa da Silva:

Primeiro momento - será passado o filme Trem da Vida. No caso, é a introdução do assunto "As Guerras" que será abordado em diversas aulas.

Em seguida, serão dispostos vários materiais que servirão como apoio para desenvolver o assunto abordado. Os materiais são:

a) Música - O senhor da Guerra do grupo Legião Urbana, a música fala sobre os países que comandam as guerras.

b) Poema-canção - Bomba de Hiroshima, de Vinícius de Moraes, retratando os efeitos da bomba.

c) Imagem da Bomba atômica, retratando a tragédia da guerra nos homens e no mundo.

d) Quadro Guernica, de Pablo Picasso, mostrando os efeitos das bombas jogadas pelos nazistas na cidade basca de Guernica.

e) Páginas do livro de Sebastião Salgado Exodos. Fotografias mostrando campos de exilados que fogem de seus países em decorrência das guerras. São pessoas que saem não porque querem mas por ne- 
cessidade de sobrevivência.

Com esses materiais, os alunos terão um panorama das diferentes guerras, das fugas e poderão pesquisar e discutir sobre

Resumo: A seção Videografia apresenta três filmes para o trabalho em sala de aula: Ninguém escreve ao coronel, Central do Brasile Trem da Vida. Com os dois primeiros filmes, a autora propõe um trabalho de pesquisa que tenha como temas a escrita e a realidade latino-americana. Com o terceiro filme, propõe um exercício que se inicia com a elaboração de perguntas sobre os temas tratados no filme e, posteriormente, orienta os alunos para simularem o papel do professor e elaborarem um projeto de pesquisa com os temas do filme Trem da Vida.

Palavras-chave: escrita, pesquisa, cinema, video, Central do Brasil, Ninguém escreve ao coronel, Trem da Vida os fundamentos e os motivos das guerras. Fica também o convite para que os professores complementem suas pesquisas com outros materiais e idéias.

(Writing as a research theme)

Abstract. The Videography section presents three films for classroom work: Ninguém escreve ao coronel, Central do Brasil and Trem da Vida. For the first two films, the author proposes research work with themes such as writing and Latin American reality. For the third film, she proposes an exercise that begins with the elaboration of questions on themes brought up by the film and, then, guides the students to simulate the teacher's role and to elaborate a research project with the themes presented in the film Trem da Vida.

Key words: writing, research, cinema, video, Central do Brasil, Ninguém escreve ao coronel, Trem da Vida 